\title{
Tumor de células de la granulosa ovárico (TCG) juvenil: a propósito de un caso
}

M. E. Pérez López, J. García Mata, J. García Gómez, J. A. Bello Gizㄹ, M. Salgado Fernández, J. L. Fírvida Pérez

\section{Resumen}

Propósito: El TCG juvenil es un tipo de tumor ovárico muy infrecuente y muy diferente a los adenocarcinomas típicos. Realizamos una revisión bibliográfica de esta enfermedad.

Material y métodos: Se presenta el caso de una mujer de 36 años con recidiva de este tumor, su abordaje terapeútico y situación actual.

Conclusiones: La cirugía es la terapia estándar. La quimioterapia se reserva en casos determinados.

Palabras clave: Carcinoma ovárico. Tumores germinales. Tumor de células de la granulosa.

Oncología, 2006; 29 (7):299-303

\section{Summary}

Purpose: Juvenile ovary granulosa cell tumor (GCT) is a rare tumor that differs from the typical ovary adenocarcinomas. We make a bibliographic review of the disease.

Material and methods: We present a 35 year old woman with relapse of an ovary GCT, indicating the administered therapy and the current situation.

Conclusions: Surgery is the gold standard therapy. Chemotherapy is to be reserved for some cases.

Key words: Ovary carcinoma. Granulosa cell tumor. Germ cell tumor. 


\section{Introducción}

El tumor de células de la granulosa ovárico (TCG) es un tipo de neoplasia muy inusual. Se caracteriza por su capacidad de secretar esteroides sexuales como los estrógenos. Su presentación es similar a otros carcinomas ováricos pero sus marcadores séricos, su comportamiento biológico, sus factores pronósticos y su manejo terapéutico deben particularizarse.

Presentamos el caso de una mujer diagnosticada de un TCG ovárico, su evolución clínica y el tratamiento realizado; se realiza una actualización de los conocimientos sobre este tumor tan infrecuente y con entidad propia.

\section{Caso clínico}

Mujer de 36 años sin antecedentes familiares oncológicos y con los siguientes antecedentes personales: menarquia: 13, G1P1A0, parto por cesárea a los 26 años, sin hábitos tóxicos, colecistectomizada por colecistitis crónica litiásica, neumonía a los 29 que no requirió ingreso. A los 30 años consultó por hirsutismo, sobrepeso y amenorrea. Refería episodios amenorreicos previos controlados con ACO (anticonceptivos orales). Presentaba un quiste ovárico en seguimiento. En la ecografía pélvica de control, a los tres meses de la previa, se objetivó un gran crecimiento de dicha lesión. Se realizó anexectomía derecha, ampliándose a histerectomía total, anexectomía izquierda, apendicectomía y omentectomía al conocerse el resultado anatomo-patológico intraoperatorio. En la pieza definitiva se confirmó un "Tumor de células de la granulosa” de $6 \mathrm{~cm}$, fragmentándose la cápsula durante el acto operatorio. Sin otra evidencia de enfermedad se estadió como Ic. La paciente desestimó recibir quimioterapia adyuvante voluntariamente. Se iniciaron seguimientos protocolizados con exploración ginecológica, TC abdomino-pélvica y radiografía de tórax normales, hasta que 6 años más tarde se observó en la exploración física una masa abdominal. La PAAF (punción-aspiración con aguja fina) fue positiva para tumor de células de la granulosa. Se realizó estudio de extensión con TC tóracoabdomino-pélvico, colonoscopia y cistoscopia y marcadores tumorales (BHCG, AFP, Ca 125, Ca 15.3, Ca 19.9 y CEA) obteniendo como único hallaz- go patológico una masa pélvica anterior e izquierda de $12 \mathrm{~cm}$ con dos componentes: uno en el interior de la cavidad pélvica, adyacente a la pared anterior vesical, y, otro contiguo que afectaba a la musculatura anterior del abdomen con engrosamiento marcado del recto anterior izquierdo hasta la región umbilical. Se procedió a la exéresis de la masa y de la aponeurosis de los músculos rectos. La paciente de nuevo desestimó quimioterapia. Dos meses más tarde sufrió nueva recidiva en pared abdominal. La TC objetivó recidiva pélvica, y en pared abdominal anterior de 7 $\mathrm{cm}$, sin otros datos de enfermedad local o a distancia. En noviembre de 2004 se realizó exéresis de la tumoración pélvica y parte de los músculos rectos del abdomen, que se rompe. Se confirmó de nuevo la recaída del TCG. La paciente aceptó el tratamiento quimioterápico y recibió esquema BEP (bleomicina, etopósido y cisplatino) que finalizó hace 6 meses. En la actualidad sigue revisiones protocolizadas cada 3 meses, sin evidencia de recidiva.

\section{Resultados}

La histología inicial y las recidivas fueron compatibles con TCG. En el tumor primario se observaba atipia nuclear importante, patrón de crecimiento sólido e índice mitótico elevado (8-12 mitosis/ campo de gran aumento), lo que unido a la ruptura del tumor y a su tamaño representaban datos de mal pronóstico.

\section{Discusión}

El TCG representa el 2-5\% de todos los carcinomas del ovario; y, el subtipo juvenil constituye un mínimo porcentaje. Como su nombre indica deriva de las células de la granulosa que forman parte del estroma ovárico y son responsables de la producción de estradiol. Se divide en adulto y juvenil, con clínica y hallazgos histopatológicos diferentes entre sí. El TCG juvenil implica sólo al 5\% de todos los TCG y afecta a niñas prepúber y mujeres menores de 30 años que pueden mostrar una pseudopubertad precoz o dolor abdominal acompañado de una masa pélvica. El $80 \%$ de estas pacientes son niñas prepuberales, aumentando su incidencia en aquéllas con enfermedad de Ollier (encondromatosis múltiple) o 
síndrome de Maffucci (discondroplasia). También se ha observado un aumento de prevalencia en pacientes sometidas a tratamientos de infertilidad. Puede aparecer incluso durante el embarazo, diagnosticándose incidentalmente, con un comportamiento similar a las ingrávidas pero mayor riesgo de complicaciones ${ }^{1,3,4}$. A pesar de parecer más indiferenciado, tiene un pronóstico más favorable porque se diagnostica tempranamente; contrariamente al subtipo adulto, cuya clínica indolente suele retrasar su sospecha y hallazgo presentando mayor tendencia a la recidiva ${ }^{2,4}$. Se presenta como irregularidad menstrual, menorragias o amenorrea y raramente infertilidad, pseudopubertad precoz en premenárquicas o hirsutismo y datos de virilización en casos con componente de células de Sertoli y Leydig, como en nuestra paciente ${ }^{1}$. El dolor abdomino-pélvico se produce por distensión secundaria a la masa ovárica, a veces como una torsión ovárica. Por su naturaleza muy vascularizada, el TCG aparece en ocasiones con ruptura intratumoral hemorrágica simulando un embarazo ectópico ${ }^{4}$. El paso inicial es el examen físico (normal o masa palpable pélvica o abdominal) y estudio ecográfico que puede revelar una masa ecogénica, quística o septada en el ovario. El pilar fundamental del tratamiento y del estadiaje es la cirugía; en los casos de TCG adulto y mujeres postmenopaúsicas es similar a la reglada para los tumores ováricos. En el subtipo juvenil y en mujeres que desean preservar su fertilidad, una vez excluida la enfermedad a distancia y realizada una biopsia endometrial para descartar afectación, se intentan medidas conservadoras como la salpingo-ooforectomía unilateral (no se realizó así en nuestro caso, no era nulípara y no deseaba más descendencia). Aquí el $90 \%$ de los casos se diagnostican en estadio $\mathrm{I}^{2}$. Histológicamente se ve una masa quística amarillenta constituida por células de la granulosa solas o en combinación con otras del estroma de los cordones sexuales y patrón de crecimiento difuso en macrofolículos (Figura 1). Presentan morfología redonda u oval con abundante citoplasma y sin el típico núcleo en "grano de café"(con una hendidura atravesándolo) del TCG adulto (Figura 2); tampoco aparecen los cuerpos de Call-Exner ${ }^{5}$. Estas peculiaridades sirven para el diagnóstico diferencial del TCG juvenil y adulto (Figura 3) y de los carcinomas indiferenciados ováricos, en ocasiones muy difícultosa.

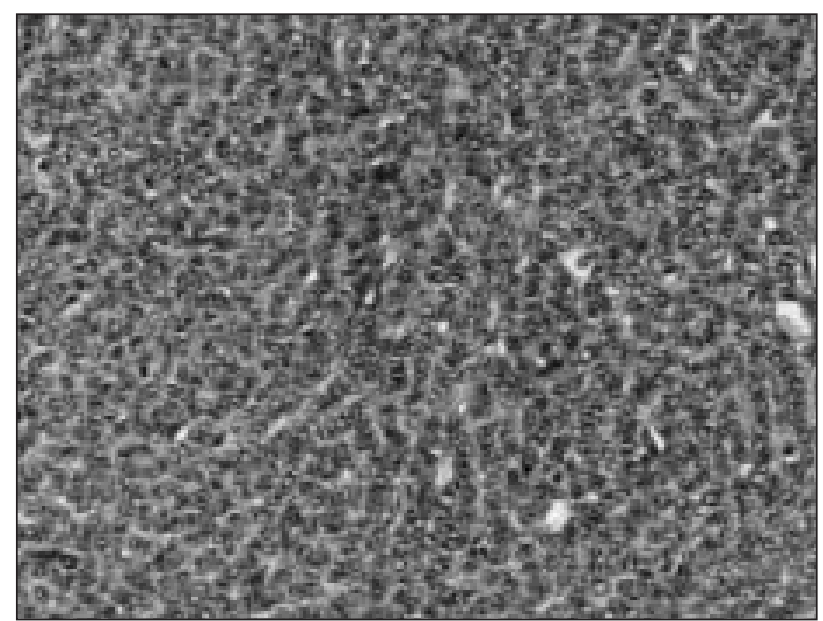

Fig. 1. Tumor de la granulosa. (H-E 200x). Patrón difuso.

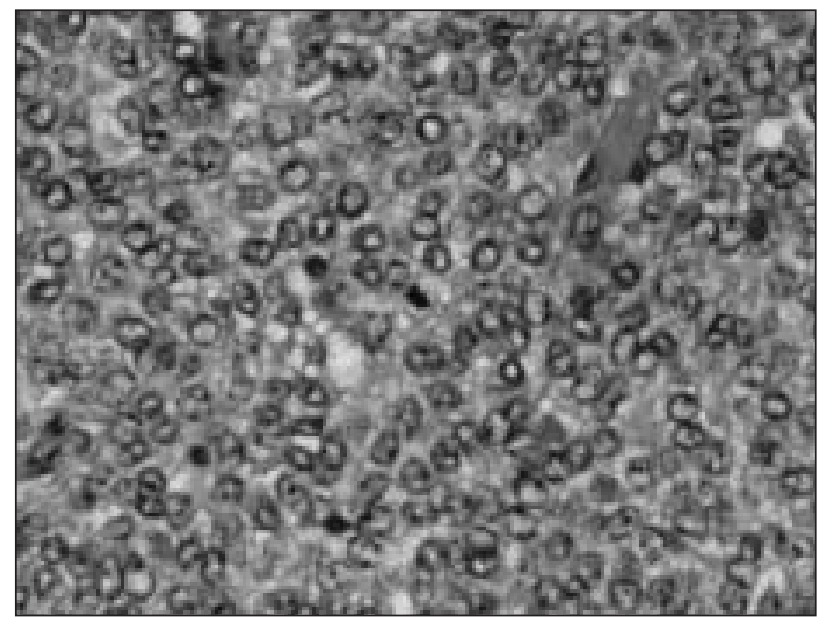

Fig. 2. Tumor de la granulosa. (H-E 400 x). Detalle de la anterior en la que se observan células de tamaño uniforme, con citoplasma eosinófilo y núcleos redondos con escaso pleomorfismo. Una figura de mitosis en el centro.

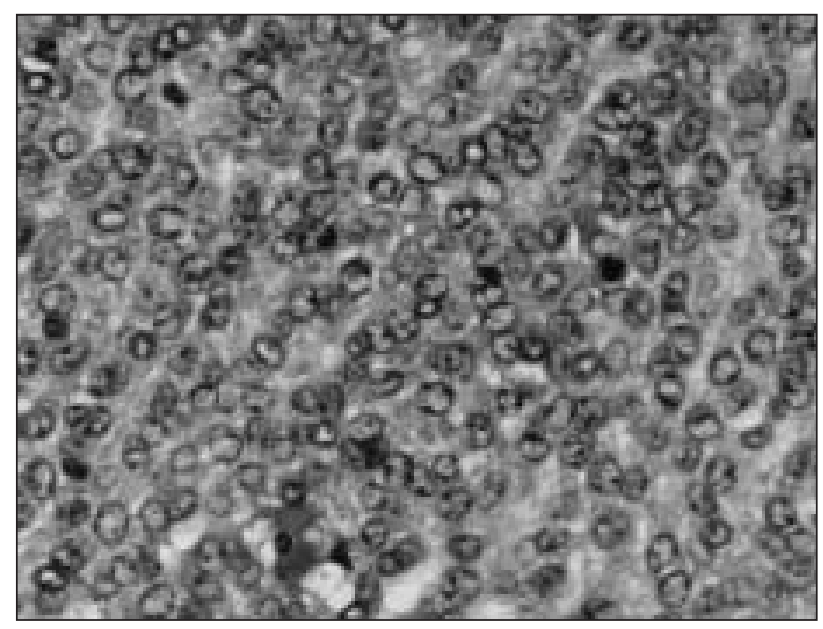

Fig. 3. Tumor de la granulosa. (H-E 400x). Similar a la anterior. 
Como marcadores tumorales se han sugerido el estradiol, la inhibina y la MIS (sustancia mulleriana inhibidora), en detrimento del Ca $125^{2,6}$, que aquí también presentaba valores normales. El primero fue identificado como una de las primeras sustancias secretadas por el TCG y responsable de muchas de sus manifestaciones ${ }^{1,4}$. Aunque podría servir como posible marcador, existen un $30 \%$ de pacientes con TCG sin elevación en su secreción, relacionada con la falta de células de la teca en el tumor. La inhibina puede estar aumentada en este proceso, aunque no específicamente, también en tumores epiteliales o mucinosos. La MSI suele elevarse incluso 12 meses antes de la recaida clínica o radiológica ${ }^{5}$.

Entre los factores de mal pronóstico se han propuesto: el estadio tumoral, el tamaño del tumor, su ruptura, su índice mitótico y anormalidades en el cariotipo $^{6,7}$. Algunos factores como la invasión linfovascular, la edad, la paridad y el estado reproductivo no son reproducibles en estudios retrospectivos.

En cuanto a la terapia, la establecida de modo estándar es la quirúrgica. No está indicada la quimioterapia adyuvante en la mayoría de los casos; sólo en aquellos de "pobre pronóstico". Es decir, en pacientes con estadios II, III y IV y estadio I con gran tamaño tumoral, alto índice mitótico o ruptura tumoral. Sin embargo, debido a la rareza de este tumor no existen ensayos randomizados que demuestren un beneficio en la supervivencia global. Parece haber, retrospectivamente, un beneficio en supervivencia libre de enfermedad ${ }^{8}$. Claramente tiene mejor pronóstico con respecto al adenocarcinoma típico, aunque hay una tendencia a la recaída local más que sistémica, que detectada precozmente puede reextirparse. Esta tendencia se mantiene en el tiempo, no siendo infrecuentes las recaídas tardías por lo que es necesario el seguimiento prolongado. Es esta una neoplasia potencialmente quimiosensible observando respuestas a drogas como adriamicina, ciclofosfamida y sobre todo análogos del platino ${ }^{8,9}$. Los regímenes con mayor respuesta son el PVB (cisplatino, vinblastina y bleomicina) y el BEP (bleomicina, etopósido y cisplatino); el último con menor neuropatía, por lo que se prefiere. Se consigue hasta un $65 \%$ de respuestas (parciales y completas) $)^{2}$, tanto en primotratamiento como en recaídas. La radioterapia estaría destinada a completar localmente un abordaje quirúrgico y con intención paliativa, en grandes masas no susceptibles de exéresis como tratamiento sintomático. Es destacable la toxicidad que puede producir una dosis alta sobre el espacio pélvico y abdominal; pero parece aumentar la supervivencia libre de recaída en las pacientes ${ }^{10}$.

En resumen, el TCG es un inusual tumor ovárico que produce síntomas derivados de la secreción de estradiol; con mucho mejor pronóstico, menor agresividad que el resto de las neoplasias ováricas y una historia natural más prolongada. La cirugía constituye el principal abordaje diagnóstico, de estadiaje, de disminución de volumen tumoral y terapéutico. La quimioterapia adyuvante sólo se recomienda en estadios precoces con factores de riesgo o en estadios avanzados, pareciendo disminuir la supervivencia libre de enfermedad y la supervivencia libre de recaída como la radioterapia. El régimen más utilizado hasta el momento es el BEP con un alto índice de respuesta, planteando siempre que sea posible el rescate quirúrgico.

\author{
Correspondencia: \\ Dra. M. E. Pérez López \\ Servicio de Oncología Médica \\ Complejo Hospitalario de Ourense \\ C/ Ramón Puga, 54-56 \\ E-32005 Ourense \\ mevaplo@hotmail.com \\ jesus.garcia.gomez@sergas.es
}




\section{Bibliografía}

1. Young RH, Dickersin GR, Scully RE. Juvenile granulosa cell tumors of the ovary: A clinicopathologic analysis of 125 cases. Am J Surg Pathol 1984; 8:575-596.

2. Schumer ST, Cannistra SA. Granulosa cell tumor of the ovary. JCO 2003; 6:1180-89.

3. Cannistra SA. Cancer of the ovary. N Engl J Med 1993; 329:1550-1559.

4. Piura B, Nemet D, Yanai-Inbar I, et al. Granulosa cell tumors of the ovary: A study of 18 cases. J Surg Oncol 1994; 55:71-77.

5. Fujimoto T, Sakuragi N, Okuyama K, et al. Histopathologic prognostic factors of adult granulosa cell tumors of the ovary. Acta Obstet Gynecol Scand 2001; 80:10691074.

6. Hildebrant RH, Rouse RV, Longacre TA.Value of inhibin in the identification of granulosa cell tumors of the ovary. Hum Pathol 1997; 28:1387-1395.

7. Miller BE, Barron BA, Wan JY, et al. Prognostic factors in adult granulosa cell tumors of the ovary. Cancer 1997; 79:1951-1955.

8. Camlibel FT, Caputo TA. Chemotherapy of granulosa cell tumors. Am J Obstet Gynecol 1983; 145:763-765.

9. Homesley HD, Bundy BN, Hurteau JA, et al. Bleomycin, etoposide and cisplatin combination therapy of ovarian granulosa cell tumors and other stromal malignancies: A Gynecologic Oncology Group study. Gynecol Oncol 1999; 72:131-137.

10. Savage P, Constenla D, Fisher C, et al. Granulosa cell tumors of the ovary: Demographics, survival and the management of advanced disease. R Coll Radiol 1998; 10:242-245. 